\title{
Influence of heat treatment on the microstructure, ultrasonic attenuation and ultrasonic velocity of GH4169 alloy
}

\author{
Xi Chen ${ }^{1,2, a}$, Zhenggan Zhou ${ }^{2, b}$ and Guanhua Wu ${ }^{1, c}$ \\ ${ }^{1}$ Ministry of Education on Key Laboratory of Nondestructive Testing, Nanchang Hangkong \\ University, Nanchang 330063 ,China; \\ ${ }^{2}$ School of Mechanical Engineering and Automation, Beihang University, Beijing 100191, China. \\ anchucx@nchu.edu.cn ,bzzhenggan@buaa.edu.cn, cwuguanhua@nchu.edu.cn
}

Keywords: GH4169 alloy, metallographic microstructure, attenuation coefficient, ultrasonic velocity.

\begin{abstract}
Microstructural changes in GH4169 alloy due to changes in annealing temperature are characterized by ultrasonic pulse-echo technique and optical microscopy. According to differential thermal analysis, the phase-transition temperature of GH4169 is $1022^{\circ} \mathrm{C}$. GH4169 alloy are heat treated at different temperature for $60 \mathrm{~min}$, and water quenched. Ultrasonic velocities and attenuation coefficient of ultrasonic waves produced with $10 \mathrm{MHz}$ transducers were evaluated for these heat-treated samples by pulse-echo method. The microstructural changes with phase-transition temperature are correlated to the ultrasonic characteristics of the alloy.
\end{abstract}

\section{Introduction}

Nickel base super alloy GH4169 (Inconel718) is a kind of precipitation strengthening type high temperature alloy. The matrix is $\gamma$ phase, the $\gamma^{\prime \prime}\left(\mathrm{Ni}_{3} \mathrm{Nb}\right)$ and $\gamma^{\prime}\left[\mathrm{Ni}_{3}(\mathrm{Al}, \mathrm{Ti})\right]$ phase is precipitated out to achieve dispersion strengthening. Then the alloy has enough high temperature strength, oxidation resistance and corrosion resistance, and good comprehensive performance [1]. GH4169 is one of the key materials in modern aviation and aerospace. The microstructure of GH4169 is sensitive to the change of thermal deformation process parameters [2]. Changing the process parameters, many parts can be manufactured to satisfy different requirements.

The ultrasonic method has the capability of detecting the characteristics of micro-texture inside the material [3]. Ultrasonic attenuation coefficient is sensitive to the average grain size, the grain size increases; the attenuation coefficient increases $[4,5,6,7,8]$. Sound velocity is affected by grain binding force and residual stress, and is sensitive to content of precipitate [9], precipitated phase [4], phase change $[10,11]$.

In the present study, ultrasonic parameters have been employed to characterize the various microstructural features in GH4169 alloy. The differential thermal analysis was used to find the phase transition temperature. According to the phase transition temperature, the alloy was heat treated at different temperatures for $60 \mathrm{~min}$, in an electrically heated muffle furnace, followed by water quenching. The changes in ultrasonic longitudinal velocities are able to characterize the hardness variation with phase transition due to heat treatment. The ultrasonic attenuation has been used to correlate the variation in the grain size with heat treatment temperature.

\section{Experimental procedure}

\subsection{Microstructure}

To investigate the influence of phase transition on the microstructure, hardness, ultrasonic velocity and attenuation, the differential thermal analysis (DSC) was done. The temperature of DSC are from $900^{\circ} \mathrm{C}$ to $1200^{\circ} \mathrm{C}$. The heating rate is $22^{\circ} \mathrm{C} / \mathrm{min}$. According to the result of DSC curve analysis, the heat treatment process parameters of GH4169 alloy are given in Table 1. Ten specimens of GH4169 alloy were cut into $\Phi 22 \mathrm{~mm} \times 22 \mathrm{~mm}$. Samples were prepared by following the standard metallographic mechanical polishing practice. Polished specimens were then etched. Microstructure 
study was carried out in a microscope, and the images were captured using soft ImageJ. The mean grain size is measured by mean diameter $\bar{D}$.

\subsection{Hardness}

The hardness of the entire specimen was also measured using Rockwell hardness tester at a test load of $60 \mathrm{~kg}$ at room temperature. A diamond indenter was used on the polished surface of the specimen. For each specimen, at least five indentations were made and the average value of readings was used for the hardness measurements.

\subsection{Ultrasonic velocity and attenuation coefficient}

Ultrasonic tests were accomplished by the contact pulse-echo method in an ultrasonic water immersion detection system using $10 \mathrm{MHz}$ longitudinal wave probe at room temperature.

Velocity is a characteristic of the material concerned and is consultant for the material for any frequency and wave-length of the sound. Ultrasonic testing (UT) is the preferred NDT technique for the characterization of the material properties. Ultrasonic testing parameters are significantly affected by changes in microstructural (or) mechanical properties of materials. Ultrasonic velocity can be estimated from the relationship,

$$
\operatorname{Velocity}(\mathrm{m} / \mathrm{s})=(2 \times \text { thickness }(\mathrm{m})) /(\text { time}(\mathrm{s}))
$$

Attenuation refers to the loss of sound energy, as the ultrasonic beam passes through the material. Attenuation co-efficient were calculated according to the relationship,

Attenuation coefficient $(\mathrm{dB} / \mathrm{mm})=\left(20 \lg \left(A_{1} / A_{2}\right)\right) /(2 \times$ thickness $(\mathrm{mm}))$

where $A_{1}$ and $A_{2}$ are the amplitude of two consecutive back wall echoes.

\section{Results and discussion}

According to the DSC curve of GH4169 (Fig.1), with the increase of temperature, sample continue to give off heat, and the exothermic maximum is achieved at $932^{\circ} \mathrm{C}$, show that there is a lot of $\delta$ phase precipitation. The derivative curve of DSC data has four inflection points, respectively at $837^{\circ} \mathrm{C}$, $907^{\circ} \mathrm{C}, 982^{\circ} \mathrm{C}, 1022^{\circ} \mathrm{C}$. That means that $\gamma$ phase begins to dissolve at $837^{\circ} \mathrm{C}$, a large amount of $\delta$ phase are began to precipitate at $907^{\circ} \mathrm{C}$, dissolve at $982^{\circ} \mathrm{C}$, and completely dissolved at $1022^{\circ} \mathrm{C}$. The phase transformation between solid and solid indeed appeared in the range of $1000^{\circ} \mathrm{C}$ to $1050^{\circ} \mathrm{C}$.

Fig.2(a) and (b) show the microstructure of GH4169 with temperature below $1022^{\circ} \mathrm{C}$. Solid solution treatment changed the grain size and shape.There are a small amount of twin crystals. The needlelike or granular $\delta$ phase distribute in the grain interior and boundary. The existence of $\delta$ hindered the growth of grain. At $1000^{\circ} \mathrm{C}$, the number of $\delta$ is obviously decreased. In the range of $1050^{\circ} \mathrm{C}$ to $1150^{\circ} \mathrm{C}$, the $\delta$ had been dissolved, a large number of twin crystals appeared, and with the temperature increasing, grain size and shape change obviously (Fig.2 (c), (d)).

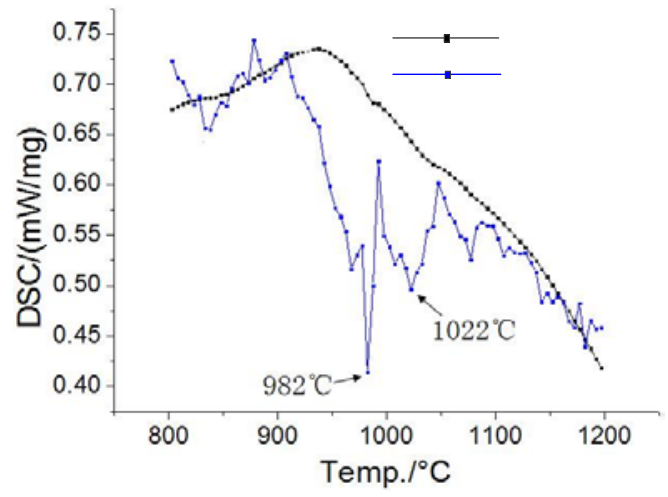

Fig. 1 DSC and derivative curve of GH416

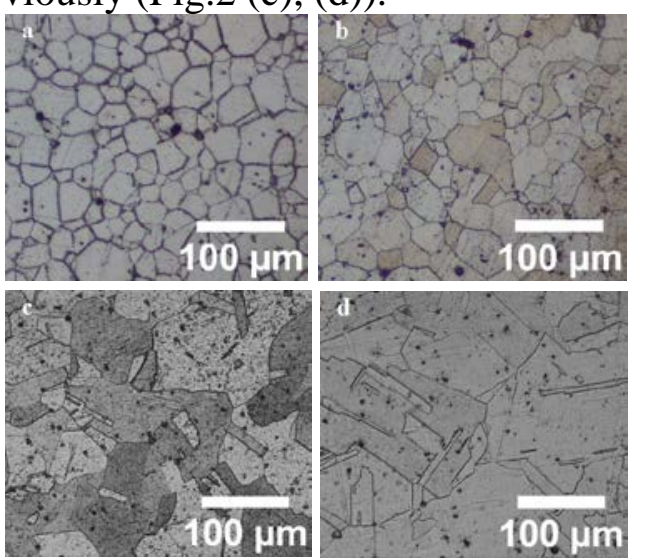

Fig.2 Microstructure of GH4169 after heat treatment; (a) $980^{\circ} \mathrm{C}$,(b) $1000^{\circ} \mathrm{C}$,(c) $1050^{\circ} \mathrm{C}$,(d) $1080^{\circ} \mathrm{C}$ 
Ultrasonic attenuation characteristics and grain size in GH4169 solution treated at different temperatures is shown in Fig. 3. The attenuation is nearly the same for GH4169 below the phase change point. With the phase change finished, the $\delta$ phase dissolved, the inhibitory effect of grain size reduce, then grain grew up sharply. The temperature increase, the grain size and the attenuation bigger. There are good positive correlations between attenuation coefficient and grain size.

Table 1 Heat treatment specification, microstructure and ultrasonic parameters of specimens

\begin{tabular}{cccccc}
\hline Number & $\begin{array}{c}\text { Heating } \\
\text { treatment }\end{array}$ & $\begin{array}{c}\text { Hardness } \\
(\text { HRA })\end{array}$ & $\begin{array}{c}\bar{D} \\
(\mu \mathrm{m})\end{array}$ & $\begin{array}{c}\text { Velocity } \\
(\mathrm{m} / \mathrm{s})\end{array}$ & $\begin{array}{c}\text { Attenuation coefficient } \\
(\mathrm{dB} / \mathrm{mm})\end{array}$ \\
\hline 1 & $900^{\circ} \mathrm{C} / 1 \mathrm{~h} / \mathrm{WQ}$ & 60.00 & 26.02597 & 5757.100 & 0.068061 \\
2 & $930^{\circ} \mathrm{C} / 1 \mathrm{~h} / \mathrm{WQ}$ & 59.63 & 26.33921 & 5755.210 & 0.074381 \\
3 & $950^{\circ} \mathrm{C} / 1 \mathrm{~h} / \mathrm{WQ}$ & 59.45 & 26.88802 & 5752.142 & 0.084954 \\
4 & $980^{\circ} \mathrm{C} / 1 \mathrm{~h} / \mathrm{WQ}$ & 59.46 & 27.19542 & 5756.010 & 0.071623 \\
5 & $1000^{\circ} \mathrm{C} / 1 \mathrm{~h} / \mathrm{WQ}$ & 59.35 & 27.57965 & 5756.790 & 0.067445 \\
6 & $1050^{\circ} \mathrm{C} / 1 \mathrm{~h} / \mathrm{WQ}$ & 55.47 & 50.22293 & 5736.000 & 0.133317 \\
7 & $1080^{\circ} \mathrm{C} / 1 \mathrm{~h} / \mathrm{WQ}$ & 55.10 & 68.42563 & 5735.330 & 0.140213 \\
8 & $1100^{\circ} \mathrm{C} / 1 \mathrm{~h} / \mathrm{WQ}$ & 54.90 & 89.01220 & 5733.428 & 0.147371 \\
9 & $1130^{\circ} \mathrm{C} / 1 \mathrm{~h} / \mathrm{WQ}$ & 53.87 & 115.63510 & 5733.910 & 0.157266 \\
10 & $1150^{\circ} \mathrm{C} / 1 \mathrm{~h} / \mathrm{WQ}$ & 53.07 & 162.92910 & 5734.157 & 0.167219 \\
\hline
\end{tabular}

Fig. 4 shows the effect of heat treatment on hardness and grain size. When the heat treatment below $1000^{\circ} \mathrm{C}$, temperature increase, the $\gamma^{\prime}$ and $\gamma^{\prime \prime}$ phase completely dissolved, the hardness was almost not influnced by temperature, as the $\delta$ phase existed. But when the $\delta$ phase was completely dissolved, hardness has a shape drop. And with grain coarsening, hardness decrease.

Changes in ultrasonic longitudinal velocity in GH4169 solution treated at different temperature are characterized and the trend is given in Fig. 5.The trend of velocity curve is same as hardness (Fig.6). When the $\delta$ phase was completely dissolved, velocity drops sharply. Below and above the phase change point, the velocity change small, almost negligible.

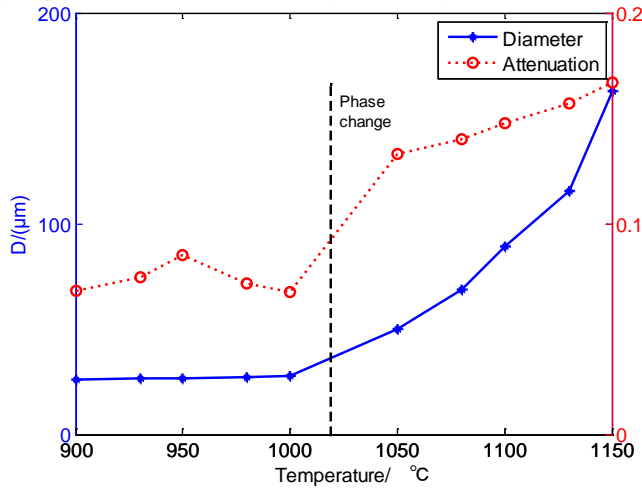

Fig.3 Variation in ultrasonic attenuation and grain size with solution treated temperature

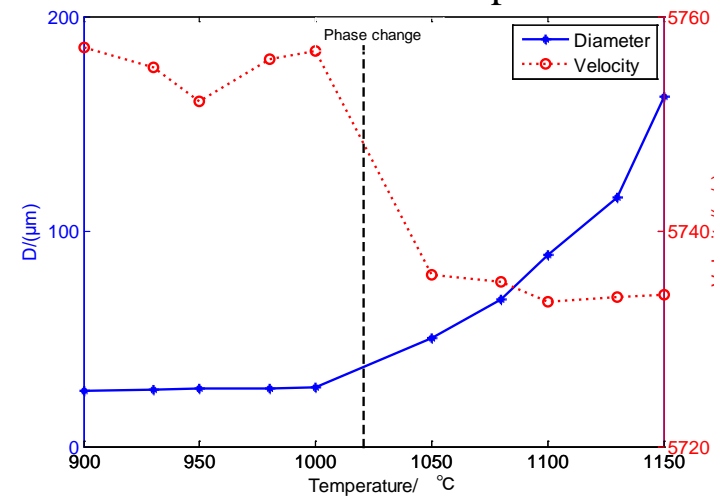

Fig.5 Variation in ultrasonic velocity and grain size with solution treated temperature

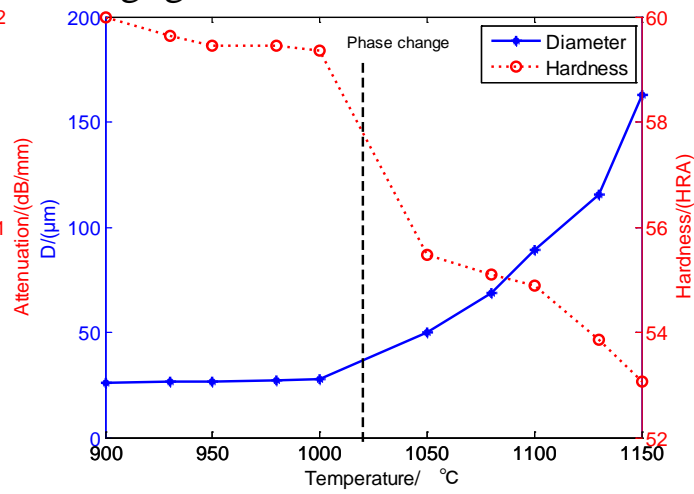

Fig.4 Variation in hardness and grain size with solution treated temperature

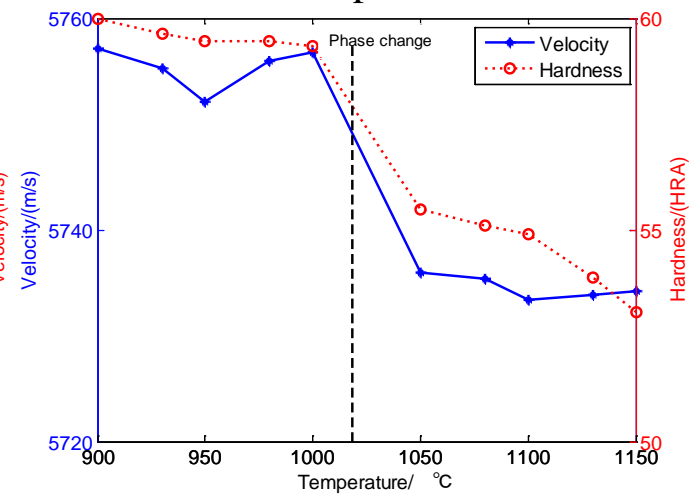

Fig.6 Variation in hardness and velocity with solution treated temperature 


\section{Conclusion}

Ultrasonic longitudinal velocity, attenuation and hardness in GH4169 solution-treated were studied. The influence of heat treatment on the microstructure of GH4169 revealed that the morphology shows appreciable change for all the heat treatment temperatures, the $\delta$ phase change point is $1022^{\circ} \mathrm{C}$, above this point the $\delta$ phase completely dissolved, grain coarsen. The results also showed that the attenuation is mainly decided by the grain size; attenuation increases steeply with increase in grain size. But the longitudinal velocity and hardness are decided by both the phase content and the grain size, and have same trend.

\section{Acknowledgement}

This work is supported by National Natural Science Foundation (NNSF) of China (No. 61202112) and the Open Fund of the Key Laboratory of Nondestructive Testing, Ministry of Education, Nanchang Hangkong University (No. ZD201529004).

\section{References}

[1]W. Yan, W.Z. Shao, Z. Liang, Dissolution behavior of $\delta$ phase and its effects on deformation mechanism of GH4169 alloy, Journal of Nonferrous Metals. 21(2011) 341-349.

[2]D. Liu, Z.J. Luo, Mathematical model for microstructure evolution of GH4169 alloy during hot working process, Chinese Journal of Nonferrous Metals. 13 (2003) 1211-1218.

[3]M. Toozandehjani, K. A. Matori, F. Ostovan, F. Mustapha, N. I. Zahari, A. Oskoueian. On the correlation between microstructural evolution and ultrasonic properties: a review. Journal of Materials Science. 50(2015): 2643-2665.

[4] K. Vijayalakshmi,V. Muthupandi, R. Jayachitra. Influence of heat treatment on the microstructure, ultrasonic attenuation and hardness of SAF 2205 duplex stainless steel, Materials Science and Engineering A, 529(2011): 447-451.

[5] V. Özkan, İsmail-H. Sarpün, A. Erol, A. Yönetken. Influence of mean grain size with ultrasonic velocity on microhardness of B4C-Fe-Ni composite. Journal of Alloys and Compounds, 574(2013): 512-519.

[6] V. Özkan, İsmail-H. Sarpün. Examining with the Sintered Temperature of Mean Grain Size of B4C--Al--Ni Composites by Ultrasonic Techniques. Acta Physica Polonica A, 121(2012): 184-186.

[7] M. Aghaie-khafri, F. Honarvar, S. Zanganeh. Characterization of Grain Size and Yield Strength in AISI 301Stainless Steel Using Ultrasonic Attenuation Measurements. Journal of Nondestructive Evaluation, 31(2012): 191-196.

[8] K. Vijayalakshmi, V. Muthupandi, R. Jayachitra. Influence of heat treatment on the microstructure, ultrasonic attenuation and hardness of SAF 2205 duplex stainless steel. Materials Science and Engineering A, 529(2011): 447-451.

[9] A. Ruiz, N. Ortiz, A. Medina, J. Y. Kim, L. J. Jacobs. Application of ultrasonic methods for early detection of thermal damage in 2205 duplex stainless steel. NDT\&E International, 54(2013): 19-26.

[10] V. H. C. D. Albuquerque, E. D. M.Silva, J. P. Leite, E. P. D. Moura, V. L. D. A. Freitas, J. M. R. S. Tavares. Spinodal decomposition mechanism study on the duplex stainless steel UNS S31803 using ultrasonic speed measurements. Materials \& Design, 31(2010): 2147-2150.

[11] E. D. M.Silva, V. H. C. D. Albuquerque, J. P. Leite, A.C.G. Varela, E.P.D. Moura, J. M. R. S. Tavares. Phase transformations evaluation on a UNS S31803 duplex stainless steel based on nondestructive testing. Materials Science and Engineering A, 516(2009): 126-130. 